\title{
Biochemical evaluation of vitamin D levels in pre diabetes, type 2 diabetes mellitus and its correlation with glycated hemoglobin
}

\author{
Suresh Nayak B ${ }^{1}$, Ajit Thakur ${ }^{2, *}$, Gayathri. L ${ }^{3}$, Prithvi Nayak ${ }^{4}$ \\ ${ }^{\mathbf{1}}$ Associate Professor, Dept. of Physiology, Dr. BR Ambedkar Medical College, Bengaluru, Karnataka, ${ }^{\mathbf{2}}$ Assistant Professor, \\ Dept. of Biochemistry, Jaipur National University Institute for Medical Sciences and Research Centre, Jaipur, Rajasthan, \\ ${ }^{3}$ Senior Paediatrician, District Hospital Chikkaballapur, Karnataka, ${ }^{4}$ Pranic Healer, GMCKS Pranic Healing Centre, Mysore, \\ Karnataka, India
}

*Corresponding Author: Ajit Thakur

Email: ajit150684@gmail.com

Received: $9^{\text {th }}$ August, 2018

Accepted: $17^{\text {th }}$ August, 2018

\begin{abstract}
Introduction: Globally, 1 billion people are suffering with deficiency or insufficiency of vitamin D. Vitamin D deficiency is also associated with metabolic disorders. This study evaluates Vitamin D levels in prediabetes, T2DM patients and its correlation with HbA1c.

Materials and Methods: This study was done in Department of Physiology in association with Department of Endocrinology, JNU Institute of Medical Sciences \& Research Center, Jaipur. A total of 155 subjected were enrolled into the study. They were divided into three groups, 65 age and gender matched healthy subjects were taken as group I (controls) (HbA1c: 5.5 to $6.5 \%$ ), 45 prediabetic subjects were taken as group II (HbA1c: 6.5 to $7.5 \%$ ) and 45 T2DM subjects were taken as group III (HbA1c: $>7.5 \%$ ). Age of the study subjects was 45 to 65 years. Serum sample was used for the estimation of random sugar (GOD-POD method) by using ERBA chemistry analyzer, vitamin D by ELISA method, using mini VIDAS and EDTA sample for HbA1c by using BIORAD D10.

Results: In this study, random blood sugar and HbA1c levels were significantly elevated in pre diabetic (group II), T2DM (group III) subjects compared with controls (group I). Significant reduction was observed in prediabetic, T2DM subjects compared to controls in respect to vitamin D levels. Negative correlation was observed between HbA1c and vitamin D.

Conclusion: In conclusion, the results of this study showed, significant reduction and negative correlation between serum vitamin D levels and HbA1c in prediabetic and T2DM patients. This study results indicates that there may be need to screen pre diabetic and T2DM patients with poor glycemic control for Vitamin D status.
\end{abstract}

Keywords: Glycated hemoglobin, Glycemic control, T2DM, Vitamin D deficiency.

\section{Introduction}

Globally, 1 billion people are suffering with deficiency or insufficiency vitamin D. ${ }^{1}$ Vitamin D deficiency, emerging as one of the nutritional risk factors for IR and T2DM. In spite of adequate sunlight exposure, studies have reported that prevalent findings of vitamin D deficiency in Indian population. ${ }^{2}$

Vitamin D plays an important role in many physiological functions, in addition to its role in blood calcium homeostasis. The diverse actions of vitamin D are mainly due to presence of its receptors in almost all tissues. Studies have reported that vitamin D plays a complex physiological role in humans. It is involved in synthesis and secretion of insulin, modulation of inflammatory response, cell maturation and differentiation. ${ }^{3-5}$

Deficiency of vitamin D causes osteoporosis, increases the risk of bone fracture, muscle weakness, malignancies, chronic inflammatory and autoimmune diseases, metabolic disorders like T2DM, Syndrome X, hypertension and CVD etc. Studies have reported that there is an association between poor glycemic control and progression to diabetes mellitus and vitamin D deficiency. Hence, vitamin D is considered as one of the potential modifier of diabetes risk. ${ }^{6,7}$
Although the exact mechanism is not clear, the association of reduced vitamin D levels in T2DM may be mediated through effects on blood glucose homeostasis and direct effect of vitamin D on the betacell function, and thus insulin secretion. ${ }^{8}$ Studies found that vitamin D deficiency leads to insulin resistance (IR). ${ }^{9}$ Decreased vitamin D level is associated with markers of impaired glucose metabolism, such as glycated hemoglobin (HbA1c). ${ }^{10-12}$

There are limited number of studies are available on the vitamin $\mathrm{D}$ levels in prediabetes and T2DM subjects. In view of increased prevalence and complications associated with diabetes mellitus, it is required to identify modifiable risk factors and implement effective preventive measures. The present study was undertaken to evaluate vitamin D levels in prediabetes, type 2 diabetes mellitus patients and its correlation with $\mathrm{HbA1c}$.

\section{Materials and Methods}

A case-control study, done in Department of Physiology in association with Department of Endocrinology, JNU Institute of Medical Sciences \& Research Center, Jaipur. A total of 155 subjected were enrolled into the study. They were divided into three 
groups, 65 age and gender matched healthy subjects were taken as group I (controls) (HbA1c: 5.5 to $6.5 \%$ ), 45 prediabetic subjects were taken as group II (HbA1c: 6.5 to $7.5 \%$ ) and 45 T2DM subjects were taken as group III (HbA1c: $>7.5 \%)$. Age of the study subjects was 45 to 65 years. Patients with a history of hypertension, renal impairment, autoimmune disorders, cerebrovascular diseases, acute respiratory failure, previous vascular events (angina, myocardial infarction, acute arterial occlusion) were excluded from the study. A detailed clinical and physical examination was done for all study participants. This study was approved by the Institutional Ethical Committee. After obtaining written informed consent from study participants, $5 \mathrm{~mL}$ random venous blood sample is collected from all subjects in vacutainers, $2 \mathrm{~mL}$ in plain tube and $3 \mathrm{~mL}$ in EDTA tube. Samples were centrifuged at $3000 \mathrm{rpm}$ for 10 minutes to obtain serum. The separated serum sample was used for the estimation of random sugar (GOD-POD method) by using ERBA chemistry analyzer, vitamin $\mathrm{D}$ by ELISA method, using mini
VIDAS and EDTA sample is used for estimation of HbA1c by using BIORAD-D10.

\section{Statistical Analysis}

Data was expressed as mean $\pm \mathrm{SD}$. $\mathrm{P}$ value $<0.05$ is considered as statistically significant. Pearson's correlation coefficient for correlation between vitamin $\mathrm{D}$ and HbA1c. Analysis was done by using SPSS software version 20.0 .

\section{Results}

Distribution of vitamin D in study groups were presented in table 1. Significantly elevated levels of Random blood sugar and HbA1c levels were observed in prediabetics (group I), T2DM (group II) subjects compared with controls (group III). Significant reduction was observed in prediabetics, T2DM subjects compared to controls in respect to vitamin D levels (Table 2). Negative correlation was observed between HbA1c and vitamin D (Table 3).

Table 1: Distribution of vitamin D levels in study groups

\begin{tabular}{|l|c|c|c|c|c|c|}
\hline \multirow{2}{*}{$\begin{array}{c}\text { Vitamin D levels } \\
(\mathbf{n g} / \mathbf{m L})\end{array}$} & \multicolumn{2}{c|}{$\begin{array}{c}\text { Group I } \\
\text { Controls (n=65) }\end{array}$} & \multicolumn{2}{c|}{$\begin{array}{c}\text { Group II } \\
\text { Prediabetes (n=45) }\end{array}$} & \multicolumn{2}{c|}{$\begin{array}{c}\text { Group III } \\
\text { T2DM (n=45) }\end{array}$} \\
\cline { 2 - 7 } & Number & $\mathbf{( \% )}$ & Number & $\mathbf{( \% )}$ & Number & $(\%)$ \\
\hline $\begin{array}{l}\text { Deficiency } \\
(10-20 \mathrm{ng} / \mathrm{mL})\end{array}$ & 12 & 18.4 & 25 & 55.5 & 39 & 86.6 \\
\hline $\begin{array}{l}\text { Insufficient } \\
(20-30 \mathrm{ng} / \mathrm{mL})\end{array}$ & 17 & 26.1 & 11 & 24.4 & 04 & 8.8 \\
\hline $\begin{array}{l}\text { Sufficient } \\
(>30 \mathrm{ng} / \mathrm{mL})\end{array}$ & 36 & 55.3 & 09 & 20 & 02 & 4.4 \\
\hline
\end{tabular}

Table 2: Comparison of study parameters between controls, pre diabetic and T2DM patients

\begin{tabular}{|l|c|c|c|}
\hline \multicolumn{1}{|c|}{ Parameters } & $\begin{array}{c}\text { Group I } \\
\text { Controls (n=65) } \\
\text { Mean } \pm \text { SD }\end{array}$ & $\begin{array}{c}\text { Group II } \\
\text { Prediabetes }(\mathbf{n}=\mathbf{4 5}) \\
\text { Mean } \pm \text { SD }\end{array}$ & $\begin{array}{c}\text { Group III } \\
\text { T2DM (n=45) } \\
\text { Mean } \pm \text { SD }\end{array}$ \\
\hline Age (years) & $41.7 \pm 8.5$ & $43.6 \pm 8.4$ & $45.2 \pm 11.1$ \\
\hline RBS (mg/dL) & $105.6 \pm 16.2$ & $141.1 \pm 22.8^{\mathrm{a}^{*}}$ & $199.5 \pm 32.5^{\mathrm{a}^{*}, \mathrm{~b}^{*}}$ \\
\hline HbA1c $(\%)$ & $5.8 \pm 0.3$ & $7.04 \pm 0.2^{\mathrm{a}^{*}}$ & $8.5 \pm 0.8^{\mathrm{a}^{*}, \mathrm{~b}^{*}}$ \\
\hline Vitamin D $(\mathrm{ng} / \mathrm{mL})$ & $32.6 \pm 12.5$ & $21.3 \pm 7.5^{\mathrm{a}^{*}}$ & $14.6 \pm 4.8^{\mathrm{a}^{*}, \mathrm{~b}^{*}}$ \\
\hline
\end{tabular}

$\mathrm{p}$ value $\leq 0.05$ considered as significant

$\mathrm{a}^{*}=$ Controls vs Pre Diabetes

$\mathrm{b}^{*}=$ Pre Diabetes vs T2DM

Table 3: Pearson's Correlation between Vitamin D and HbA1c

\begin{tabular}{|c|c|}
\hline Parameters & Correlation Coefficient (r) \\
\hline HbA1c & $-0.418^{* *}$ \\
\hline
\end{tabular}

$* *$ Correlation is significant at the 0.01 level (2-tailed).

\section{Discussion}

The present study was aimed to evaluate the Vitamin D levels in prediabetes, type 2 diabetes mellitus patients and its correlation with HbA1c. The study results showed that there is a significant reduction in vitamin D levels in prediabetes, T2DM patients compared to controls ${ }^{13-15}$ and negative correlation between vitamin D levels and HbA1c.

Vitamin D plays a significant role in the glucose metabolism. In the beta-cells of the pancreas, vitamin D stimulates the secretion of insulin and increases intracellular $\mathrm{Ca}^{2+}$ levels, which attenuates the synthesis of insulin. Vitamin D also required for insulin sensitivity in peripheral uscle and adipose tissue. Low- 
grade inflammation is seen in type 2 diabetes mellitus, vitamin $\mathrm{D}$ is an anti-inflammatory in nature, it exerts its beneficial effects on glycemic control and prevention of complications. Vitamin D influences the insulin sensitivity through several mechanisms. This is due to presence of vitamin $\mathrm{D}$ receptors in pancreatic $\beta$-cells and vitamin $\mathrm{D}$ response element in human insulin gene support a direct effect of vitamin D on synthesis and secretion of insulin. Vitamin D stimulates the expression of insulin receptors and increases the transportation of glucose in peripheral tissues. ${ }^{16-17}$

Vitamin D plays an important role in the regulation of blood calcium homeostasis and it is also involved in the regulation of around 200 genes. In India, inadequate exposure to sunlight, obesity, sedentary lifestyle, decreased physical activity, malabsorption, skin pigmentation are possible reasons for reduced vitamin D levels. ${ }^{18}$ Reduced vitamin D levels accelerates the systemic inflammation and worsens glycemic control among diabetics enhancing their complications. ${ }^{19}$

The progression of prediabetes to type 2 diabetes occurs over many years before the development of frank diabetes. Depending upon the degree of insulin resistance and reduced insulin secretion this may progress to diabetes mellitus. Vitamin D exerts it's action in a variety of cells through its receptor. Molecular evidences have found that pancreatic $\beta$-cells express both cytolic/nuclear VDR, thus enhances $\beta$ cells function. Additionally, vitamin $\mathrm{D}$ protects pancreatic $\beta$ cells from immune attack. Vitamin D inhibits the release of the pro-inflammatory cytokines, TNF $\alpha$ and regulates the activity of TLR and TLR 4 proteins. Studies indicate that Vitamin D has importance not only for cardiovascular health, but also for the immune response. Several studies support that supplementation of vitamin D may affect glucose homeostasis and improve insulin resistance. ${ }^{20}$

Lack of physical exercise is also one of the common risk factor in the etiology of diabetes mellitus and vitamin D deficiency. Vitamin D status would be improved by physical exercise, and also helpful to prevent development and progression of T2DM. ${ }^{21,22}$

In this study, HbAlc levels were significantly elevated in prediabetes and T2DM than controls and it is negatively correlated with vitamin $\mathrm{D}$ in prediabetes and type 2 diabetes mellitus patients. The present study results are in accordance with other studies. ${ }^{23,24}$

The results of the present study suggests that, maintenance of vitamin D levels in normal ranges may be helpful to keep blood sugar in normal range. Individuals with increased HbAlc should be screened for vitamin D status and vice versa. Vitamin D supplementation can delay the onset or progression of diabetes mellitus needs to be established.

\section{Conclusion}

In conclusion, the results of this study showed, significantly elevated levels of Random blood sugar and $\mathrm{HbA} 1 \mathrm{c}$ levels were observed in prediabetics, T2DM subjects compared with controls. Significant reduction was observed in prediabetics, T2DM subjects compared to controls in respect to vitamin D levels. Negative correlation was observed between $\mathrm{HbA} 1 \mathrm{c}$ and vitamin $\mathrm{D}$. This study results indicates that there may be need to screen prediabetic and T2DM patients with poor glycemic control for Vitamin D status. The main limitation of this study is small sample size. Therefore, further large prospective studies are needed.

\section{Conflict of Interest: Nil}

\section{Acknowledgements: Nil}

\section{Funding: Nil}

\section{References}

1. Mukherjee Brijesh and Patra Saurav. Prevalence of Vitamin D Deficiency in Type 2 Diabetes Mellitus Patients and its Correlation with Glycemic Control. International Journal of Bioassays. 2014;3(09):33133317.

2. Penckofer S, Kouba J Wallis DE, Emanuele MA. Vitamin $\mathrm{D}$ and diabetes: let the sunshine in. Diabetes Education. 2008:34(6):39-40.

3. Shaafie IA, Hesham RA, Basha AA. Vitamin D status in type 2 diabetic patients and its association with glycemic control, lipids \& microalbuminuria: A pilot study. Gulf Medical Journal. 2013;2(S1):S6-S13.

4. Nagpal S, Na S, Rathnachalam R. Noncalcemic actions of vitamin D receptor ligands. Endocrinology Reviewes. 2005;26:662-687.

5. Holick MF. Vitamin D: importance in the prevention of cancers, type 1 diabetes, heart disease, and osteoporosis. American Journal of Clinical Nutrition. 2004;79(3):362371 .

6. Liu E, Meigs JB, Pittas AG, Economos CD, Keown NC, Booth SL, and Jacques PF. Predicted 25- hydroxy vitamin D score and incident type 2 diabetes in the Framingham offspring study. American Journal Clinical Nutrition. 2010;91(6):1627-1633.

7. Hypponen E, Power C. Vitamin D status and glucose homeostasis in the 1958 British birth cohort: the role of obesity. Diabetes Care. 2006;29:2244-2246.

8. Alvarez JA, Ashraf A. Role of vitamin D in insulin secretion and insulin sensitivity for glucose homeostasis. International Journal of Endocrinology. 2010;2010:351385 .

9. Teegarden D, Donkin SS. Vitamin D: emerging new roles in insulin sensitivity. Nutrition Research Reviews. 2009;22:82-92.

10. Kositsawat JMDM, Freeman VLM, Gerber BSMM, Geraci SM. Association of A1C levels with vitamin D status in U.S. adults: data from the National Health and Nutrition Examination Survey. Diabetes Care. 2010;33:1236-1238.

11. Forouhi NG, Luan J, Cooper A, Boucher BJ, Wareham NJ. Baseline serum 25-hydroxyvitamin D is predictive of future glycemic status and insulin resistance: the Medical Research Council Ely Prospective Study 1990-2000. Diabetes. 2008;57:2619-2625. 
12. Christine Dalgard, Mria Skaalum Petersen, Pal Weihe, Philippee Grandjean. Vitamin D ststus in relation to glucose metabolism and type 2 diabetes in septuagenarians. Diabetes Care. 2011;34:1284-1288.

13. Manju. M, Sasmita Mishra, B.D. Toora, S. Vithiyavathy. Relationship between serum Vitamin D and insulin resistance in pre-diabetic and diabetic states- A comparative study. International Journal of Clinical Biochemistry and Research. 2018;5(1):91-96.

14. Yun Gao, Tianpeng Zheng, Xingwu Ran, Yan Ren, Tao Chen, Li Zhong, Donge Yan et al. Vitamin D and Incidence of Prediabetes or Type 2 Diabetes: A FourYear Follow-Up Community-Based Study. Disease Markers. 2018; 2018:1-8.

15. Munibuddin M Ahmed, Urjita S Zingade, Khaled M Badaam and Samina T Khan. Prevalence of Vitamin D Deficiency in Prediabetes and its Correlation with Glycemic Indices: A Cross- Sectional Pilot Study. Research Journal of Pharmaceutical, Biological and Chemical Sciences. 2014;5(4):1340-1344.

16. Ozfirat Z, Chowdhury TA. Vitamin D deficiency and Type 2 diabetes. Postgraduate Medical Journal. 2007;357: 266-281.

17. Pittas AG, Lau J, Hu FB, Dawson, Hughes B. The role of Vitamin D and calcium in type 2 diabetes. A systematic review and meta-analysis. Journal of Clinical Endocrinology and Metabolism. 2007;92:2017-2029.

18. Londhey V. Vitamin D Deficiency: Indian Scenario JAPI. 2011;59:695-696.

19. Muhairi SJ, Mehairi AE, Khouri AA, Naqbi MM, Maskari FA, Al Kaabi J et al. Vitamin D deficiency among healthy adolescents in Al Ain, United Arab Emirates. BMC Public Health. 2013;13:33.
20. Srinath K. M., Shashidhara K. C., Rajeev Reddy G, Madhu Basavegowda, Kishaloy Debnath and Mahesh M.G. Pattern of vitamin D status in prediabetic individuals: a case control study at tertiary hospital in South India. International Journal of Research in Medical Sciences. 2016;4(4):1010-1015.

21. Savastano S, Somma CD, Colao A. Vitamin-D \& prediabetes: a promising ménage in the Indian Scenario. Indian Journal of Medical Research. 2013;138:829-830.

22. Shilpa Balaji Asegaonkar. Vitamin D and Type 2 Diabetes Mellitus: Indian Perspectives. Journal of Diabetic Complications \& Medicine. 2016;1(3):1-4.

23. Anyanwu Anthony Chinedu, O. A. Fasanmade1, H. A. B. Coker, A. E. Ohwovoriole. Relationship between Vitamin D Levels and Glycaemic Control in Type 2 Diabetes Mellitus Patients in Lagos, Nigeria. Journal of Diabetology. 2017;8:32-36.

24. Kositsawat J, Freeman VL, Gerber BS, Geraci S. Association of A1C levels with Vitamin D status in U.S. adults: Data from the National Health and Nutrition Examination Survey. Diabetes Care. 2010;33:1236-1238.

How to cite this article: Nayak S.B, Thakur A, Gayathri. L, Nayak P. Biochemical evaluation of vitamin $\mathrm{D}$ levels in pre diabetes, type 2 diabetes mellitus and its correlation with glycated hemoglobin. Indian J Clin Anat Physiol.2018;5(4):474-477. 